8. The Hindu. Who are Chakmas? Sep. 14, 2017 [Электронный ресурс]. Режим доступа: https://www.thehindu.com/news/national/who-are-chakmas/article19682129.ece (Дата обращения 14.05.2019)

9. Institute of peace and conflict studies. Arunachal Pradesh: The Chakma-Hajong Refugee Crisis - 2005. [Электронный ресурс]. Режим доступа: http://www.ipcs.org/focusthemsel.php?articleNo=1687 (Дата обращения 22.05.2019)

10. Timesofindia. 400 Chakmas escape to Tripura from Arunachal Pradesh - 2019 . [Электронный ресурс]. Pежим доступа: https://timesofindia.indiatimes.com/city/agartala/400-chakmas-escape-to-tripura-fromarunachal-pradesh/articleshow/67813863.cms (Дата обращения 21.05.2019)

11. The Hindu. What is the Citizenship (Amendment) Bill, 2016? - 2018. [Электронный ресурс]. Режим доступа: https://www.thehindu.com/news/national/other-states/what-is-the-citizenship-amendment-bill2016/article23999348.ece (Дата обращения 14.05.2019)

12. Hindustantimes. Arunachal assembly resolution on citizenship to Chakmas, Hajongs kicks up fresh row 2017. [Электронный ресурс]. Режим доступа: https://www.hindustantimes.com/india-news/arunachalassembly-resolution-on-citizenship-to-chakmas-hajongs-kicks-up-fresh-row/story1kom96LXBuC0BM80LeNy7L.html (Дата обращения 18.05.2019)

Kontcova Elizaveta Andreevna, postgraduate student, Saint-Petersburg State University (7-9, Universitetskaya Emb., St. Petersburg, 199034, Russian Federation). E-mail: elizabethkontsova@gmail.com

\title{
CHAKMA REFUGEES: PROBLEMS AND PROSPECTS
}

\section{Abstract}

In order to achieve sustainable development world society should pay attention to a single refugee case and try to find solutions to meet their needs, thus article considers Chakma refugees' problems and prospects to their resolutions. First part of the article studies history of Chakma people. Second part reviews main reasons of mass forced migration. Third part of the article is to consider attempts and current issues of settlement for Chakma refugees. Keywords: Chakma, refugee, forced migration, Southern Asia, regional security, Convention on the status of refugees, political consequences, breeding people, political autonomy.

\section{РАЗГРАНИЧЕНИЕ ПОНЯТИЙ «ЭТНОС» И «НАЦИЯ» В УСЛОВИЯХ НАЦИОНАЛЬНО-ТЕРРИТОРИАЛЬНОГО УСТРОЙСТВА РФ}

\author{
Рамазанова аспирант, Северо-Западный институт управления Российской академии \\ Патимат народного хозяйства и государственной службы при Президенте РФ \\ Рамазановна (199178, Россия, г. Санкт-Петербург, Средний пр. В.0., 57/43). \\ E-mail: pati-agent@mail.ru
}

\section{Аннотация}

Статья посвящена актуальной в настоящее время проблеме межэтнических и межнациональных отношений между различными социальными группами и перспективам развития в России благоприятной ситуации в вопросах этнического взаимодействия. В статье рассматривается терминология таких понятий, как «этнос», «нация», «народ», изучается вопрос поэтапного развития одного понятия из другого и современного применения этих терминов в настоящее время. Особое внимание было уделено такому понятию, как «нация» в его негативном ключе и его воздействию на этнические группы внутри государств. В заключение раскрываются перспективы построения в России полиэтнического народа, объединенного на основании общности таких факторов, как: исторический путь, ценности и идеи.

Ключевые слова: этнос, нация, этническая группа, национально-территориальное устройство, Российская Федерация, народ, социальные группы, полиэтнический народ, этническое взаимодействие.

Актуальность темы исследования заключается в рассмотрении понятий «этнос» и «нация» и их взаимосвязи с национально-территориальным устройством Российской Федерации.

Как правило, мы используем такие понятия, как «нация», «этнос» или «народ» зачастую в одинаковом ключе, определяя их в качестве синонимов. Это вполне допустимо, однако с обязательным учетом того, что при более глубоком изучении между каждым из них в частности появляется разница, которая заставляет по-особенному взглянуть на данную терминологию и ее роль в развитии социологии и политологии.

Само определение термина «этнос» ранее традиционно использовалось применимо к людям с общим происхождением, в античную эпоху так именовали простые сообщества людей. Значительно позже термином «этнос» были наделены варварские племена.

При написании статьи автором были исследованы труды отечественных и зарубежных учёных, это в частности: А.А. Ашхамахова, А.А. Дадашев, А.Г. Дугин, а также А.Б. Паскачев, Ю.И. Семенов 
и В.А. Тишков. Также следует отметить, что основой определения С.М. Широкогорова является идея множественности этносов, что подразумевает тот факт, что традиции, обычаи а также жизненный уклад и ряд других социокультурных факторов, которые присущи одному этносу, в любом случае отличаются от аналогичных факторов других этносов.

В зарубежной литературе чаще всего для данного определения используется термин «этничность». В частности, Макс Вебер рассматривает этничность как обязательную принадлежность человека к определенной группе других людей, у которых есть общие цели, задачи, а главное, что и обозначает их как этнос - однородность в вопросах культуры и верование в мифологическое общее происхождение. Согласно утверждению Макса Вебера, само понятие этничности (в зарубежной литературе чаще использовалось это понятие вместо термина «этнос») подразумевает принадлежность к определенной этнической группе, объединительными факторами для которой являются культурная однородность и вера в общность происхождения [3, с. 160]. Путаница в терминологии продолжает сохраняться, в частности даже указ Президента Российской Федерации «О Стратегии государственной национальной политики Российской Федерации на период до 2025 года» содержит такие несоответствия 1 .

Говоря о России, стоит отметить, что наша страна является уникальной в этом ключе, так как разнообразие этнического состава в РФ огромно. Согласно официальным данным Росстата, в нашем государстве проживают около ста восьмидесяти этнических групп, каждая из которых имеет свой собственный язык, хранит свои уникальные традиции, передает из поколения в поколение свою самобытную мифологию, мировоззрение и систему ценностей. Такое многообразие вполне оправданно можно считать одним из национальных достояний Российской Федерации. Наша общая российская культура становится шире и многограннее от каждого языка, каждого мифа и каждой традиции, привнесенной из различных этнических групп.

При этом существует также мнение о том, что подобная полиэтничность, при необдуманных и неосторожных действиях со стороны центральной власти государства, может стать «ахилессовой пятой» России. Многие известные американские геополитики, в частности Генри Киссинджер и Збигнев Бжезинский многократно в своих научных трудах озвучивали идею о разделении срединной части Евразии, «Хартленда», на несколько национальных государств, контроль над которыми намного проще осуществлять, чем над СССР или РФ.

Подобный сценарий может быть реализован нашими геополитическими противниками только путем разжигания межэтнических противоречий внутри Российского государства, а также путем внедрения подконтрольных им людей во внутриполитическую сферу России, с помощью новейших социальных технологий, масс-медиа и т.д. По этой причине к вопросу о регулировании межэтнических взаимоотношений в нашем государстве правительство должно подходить со взвешенным, тщательно продуманным подходом и проработанной стратегией. Основной задачей для подобной стратегии является формирование российского общества, которое будет устойчиво к межэтническим конфликтам, тем самым исключая возможность его раскола.

Однако, прежде чем приступить к обсуждению различных вариантов стратегии национальной российской политики и искать новые пути решения вытекающих из этого проблем, необходимо определиться с базовыми понятиями в области этносоциологии. Такие эксперты в этой области, как А.Г. Дугин, отмечают тот факт, что частичная неопределенность в понимании самих этносоциологических терминов существует, в том числе и в научной среде. В первую очередь, для понимания этого вопроса необходимо четкое разграничение таких фундаментальных понятий этносоциологии, как нация и национальность, этнос и народ, а затем вкратце пройтись по тому курсу регулирования межэтнических взаимоотношений, предлагаемый нам представителями консервативного евразийского движения.

Понятием, которое хотелось бы рассмотреть первым в рамках данной статьи, является понятие «этнос». С. Широкогоров и М. Вебер таким образом определяют этот термин - этнос есть группа людей, которые говорят на одном языке, а также имеют общее происхождение и традиции.

Одним из определяющих факторов в жизни этноса является его язык. По словам немецкого философа М. Хайдеггера, язык есть «дом бытия». Это обусловлено тем, что именно язык в первую очередь определяет принадлежность человека к тому или иному этносу.

Таким образом, например, можно утверждать, что русскими являются все люди, которые думают и говорят по-русски, а страна их пребывания в данном аспекте не играет никакой роли.

\footnotetext{
1 Указ Президента РФ № 1666 «О Стратегии государственной национальной политики Российской Федерации на период до 2025 года» от 19.12.2012
} 
А. Г. Дугин определяет этнос как простое общество, зачастую с традиционным укладом развития, связь которого ощущается через общность территории и единство нравственных законов, системы обычаев и традиций, а также знаковой системой [2].

Есть также и иное определение понятия «этнос», наверное, самое необычное из всех. Оно категорически отрицает какую-либо связь между образованием этноса и с политическими, экономическими, языковыми и культурными факторами [1]. Подобный подход позволяет рассмотреть этнос в качестве группы, удовлетворяющей потребность каждого индивида - коллективную жизнедеятельность, что нивелирует роль всего остального, оставляя только идентичность самосознания. Таким образом, можно утверждать о том, что в настоящее время однозначного определения термину «этнос» не существует.

Кроме того, как показывает практика, источником происхождения этноса в подавляющем большинстве случаев становится вера в общего предка. Тот факт, что само существование общего предка весьма трудно доказать, и одновременно с этим трудно и опровергнуть, давал возможность вступить в этнос любому человеку, который заявлял о своей причастности к мифологическому происхождению остальных членов этнической группы.

Этнос неделим - обязательное условие его существования. Этнос может быть уничтожен при любой попытке вторжения в культуру этноса, его расчленения или любого другого нарушения естественного хода. В этносе отсутствует строгая стратификация, для которой характерны подобные семейным отношения, что наделяет авторитетом по обыкновению старшего члена этнической группы. Этнос является статической, консервативной единицей, способной к существованию в практически неизменном состоянии в течение довольно длительного отрезка времени, а также успешно сохранять язык и культуру [5].

Из вышеперечисленного можно сделать следующий выбор - для того, чтобы сформироваться в народ, этносам необходимо найти ряд объединительных факторов, таких как общая цель, увеличение структурированности социальных процессов и преобразования в области культуры.

Также одним из базовых этносоциологических определений определяют термин «народ». Народы формируются тогда, когда в ходе определенного витка исторического процесса этнические группы становятся вынуждены вступать друг с другом во взаимоотношения, что лишает их застойного состояния и дает толчок к развитию, формируя из их общности народы. При этом также возможен и иной процесс, когда этносы поглощаются уже сформировавшимся активным народом, причем зачастую это происходит путями активного вмешательства в их внутреннюю жизнь, вплоть до военного.

Таким образом, можно сформулировать определение народа как общность объединения этносов, вступившее в историю и ставшее одним из полноценных акторов на международной арене. При этом социум становится очень дифференцированием. После образования единого народа, для этнических групп становится возможным формирование таких важнейших элементов, как государство, религия и цивилизация.

Процесс появления народа из этноса рассмотреть на примере еврейского народа: «Существуя много лет как этнос, евреи в свое время вступили в историю, находясь в состоянии рассеивания, длительность которого составляла более 2000 лет, однако при этом им удалось сохранить свою идентичность и стать народом, а затем придя к высшему достижению самоопределившихся народов - созданию своего национального государства, Израиля. Аналогичным образом, понятие «народ» актуально и применительно к российскому народу, который сформировался из большого количества этносов.

При этом определение "народ" является по-своему уникальным для России, так как по большей мере не имеет аналогичной терминологии в других языках, кроме русского. На английский слово «народ» переводится, как «реоple», на испанский - «el pueblo» то есть «люди» как общее количество, в немецком «народ» - «das Volk», по звучанию схожее с русским «полк», также обозначающий определенную общность людей. Так или иначе, ни один другой язык не может отразить это емкое русское понятие, «народ», которым мы привыкли обозначать колоссальную массу с этнической точки зрения разнородного населения, которое объединено общими целями и историей

Следующее понятие, нация, подразумевает под собой общественную единицу, выражающую политическое единение людей, которые проживают в одном и том же государстве. Слово «нация» происходит от латинского термина «natio», обозначающего общность людей, которые имеют единое происхождение в территориальном вопросе. В момент образования нации культурные различия между этносами, которые образуют государство, начинают стираться под давлением. Нацию можно сравнить с плавильным котлом для этносоциальных групп, так для ее создания уничтожаются, такие традиционные формы идентичности, как этническая, культурная, и другие, вплоть до 
религиозной. Признаками формирования нации, как правило, является полная ликвидация языковых отличий между этносами, и навязывание на государственном уровне языка, принадлежащего наиболее многочисленной этнической группы в качестве единственно возможного для использования.

Уже многократно упоминаемый в работе Дугин А. Г. имел свой собственный взгляд на нацию, как на политическое сообщество, который вообще не подразумевал какое-либо влияние этноса в качестве основы. По его мнению, сама нация может быть основана исключительно на общности интересов, причем обязательно экономико-политического характера. Здесь подчеркивается тот факт, что с появлением нации исчезает общая идентичность, которую заменяет индивидуальная, в форме наделения человека статусом гражданина. Элементы и этноса и народа сохраняются в нации, однако это уже следует считать совершенно другим, более высоким уровнем [2].

Французский термин «Etat-Nation», «государство-нация», подразумевает государство, в котором возможность к существованию имеет только одна нация. В подобном государстве главным определением принадлежности к нации является формальный признак гражданства. При этом синонимичными и тождественными друг другу понятиями в таком государстве являются национальная принадлежность и, собственно, гражданство. Такие страны, как Франция и США на протяжении многих веков целенаправленно проводилась и проводится политика стирания этнических различий. При этом только индивидуальная идентичность гражданина такой страны является единственной охраняемой ценностью, другие формы идентичности уничтожаются по запросу политических интересов правящей элиты государства.

Постсоветский период богат на исследователей в этом вопросе, в частности Абдулатипов Р.Г. склонен объяснять термин «нация» как некую общность, основанную на этническом признаке, что ставит его в противоборство мнению Тишкова В. А., который все же склонен видеть в нации сообщество людей, объединенных в первую очередь гражданством.

С исторической точки зрения, современное смысловое определения такого термина, как «нация» является едва ли не более сложным, чем определение этноса. В российской научной среде традиционно используется определение нации, как определенного уровня этнической группы, возникшей в ходе исторического процесса и сохраняющаяся посредством взаимодействия с людьми, наделенными схожими взглядами, культурой и психологией. В списке определений появляются такие словосочетания, как «межнациональные отношения» и «национальная политика».

Таким образом, этнос можно определить, как некую группу людей, объединенных следующими факторами:

- общность традиций и особенности культуры;

- схожесть языка (особенно в случае наличия большого количества языковых диалектов внутри одного этноса;

- отчетливое осознание того, что у представителей одного этноса присутствует общее происхождение, что отличает их от других этносов

Понятие «национальность» - термин был введен австрийским марксистом О. Бауэром, и определяется как народ, переходящий в новое для себя состояние - нация. В советской политикосоциальной сфере научной деятельности под национальностью подразумевалась этничность, что в корне не соответствует общемировому научному определению данного термина [4]. Для мировой политологической практики, именование этноса, входящего в государства, термином «национальность» сродни призыву к сепаратизму. Подобное расхождение понятий присутствует и сейчас, так как согласно Конституции РФ, мы есть многонациональный русский народ, что по европейской терминологии обрекает страну на распад на несколько государств-наций. В этом случае намного более приемлем термин «полиэтнический», что подразумевает народ, единый в рамках одного государства, но при этом состоящий из определенных групп населения, отличающихся от друг друга происхождением и культурой.

В таком случае, какое будущее ожидает Россию - формирование единого народа или нации? Почему считается, что образование нации, с точки зрения многочисленных представителей евразийского движения, является нецелесообразным и даже вредным для России? Причина этому в том, что процесс образования нации в той или иной степени является обезличиванием народа, ликвидацией всех форм идентичности, за исключением индивидуальной. С созданием нации уничтожается так называемый культурный код этноса, а за ним происходит также и утрата системы ценностей и смыслов, которая давала возможность членам этнического сообщества осуществлять жизнедеятельность в рамках социальной группы и бороться за место под солнцем. Ликвидация же этнических различий и навязывание всеобщего либерального «суррогата культуры» неизбежно приводит к исчезновению исторически сложившихся традиционных смыслов. Такой народ, в случае 
насильственного превращения в нацию, лишается стимуляции к развитию, прогрессированию, защите своей исконной территории и т.д. Последствия, губительные для народа, так или иначе становятся губительными и для нации - она может полностью угаснуть и исчезнуть с исторической арены.

Существует также и более перспективный вариант для развития нашего общества, который предполагает поэтапный переход к созданию одновременно единого и полиэтнического народа, способного, несмотря на свое однообразие, к объединению на основании общности исторического пути, системы ценностей и единой народной идеи.

Есть также мнение, что наиболее оптимальный, а возможно даже и единственный вариант для нормального функционирование российского общества - создание империи. Под «империей» большинство социологов понимает сочетание таких понятий, как стратегическое единство и полиэтничность, что и приемлемо в настоящий момент для России [5]

У России богатый исторический опыт в построении империй, разношерстных по своему этническому составу, причем при учете всех военных, политических, экономических и культурных достижениях, этот опыт вполне можно назвать удачным - начиная от Русского царства, уже тогда полиэтнического, и заканчивая коммунистической империей Советского Союза.

Если подвести итог всем примечательным особенностям, характеризующим нынешнюю Россию, можно очевидно констатировать то, что:

- этнодемографический состав в современной России является одним из сложнейших в мире;

- население этнических групп в России в большинстве своем компактно расположены на своих этнических территории (несмотря на межнациональную и межрегиональную подвижность населения и на рост многонациональности республик);

- как в дореволюционную эпоху, так и в течение многих десятилетий после нее в период господства тоталитарного и сверхцентрализованного режима большинство народов России были лишены реальной государственности на национальной основе;

- социальный прогресс способствовал национальному самосознанию этнических групп в России, усилившегося крушением тоталитаризма и переходом к демократическому режиму;

- до сих пор не были полностью преодолены последствия тех грубых ошибок, которые были допущены советской властью в осуществлении национальной политики в отношение этнических групп;

Также следует учесть то, что наша страна сравнительно недавно вышла из глубокого социально-экономического кризиса, после чего в течение 18 лет вносит демократические преобразования, поэтому создание в РФ гражданского общества и правового государства является постепенным процессом, учитывая периодические обострения межэтнических отношений в ряде регионов.

В заключение следует отметить, что приблизительно за сто лет последовательного совершенствования в сферах гуманизма и демократии, для многонационального государства появляется реальная возможность создания такой социально-политической системы, которая была бы способна особенно чутким и внимательным образом учитывать интересы всех народов, проживающих на территории страны, вследствие чего будет исключена возможность появления такой ситуации, когда национальные меньшинства начнут нуждаться в особенных специфических национальнополитических институтах и сможет довольствоваться наличием национально-культурной автономии и общегражданского равноправия.

\section{Литература}

1. Ашхамахова А.А., Дадашев А.А. Соотношение понятий «Этнос» и «Нация» в социальной философии // Общество: философия, история, культура. 2017. № 7. С. 23-27.

2. Дугин А.Г. Социология этноса. Монография. М., 2014. С. 8-14.

3. Паскачев А.Б. Национальная политика в России (от империи - к единой российской нации). - М.; Ярославль: Литера, 2016. 245 с.

4. Семенов Ю.И. Общество, население этнос // Этнос, нации, ценности. Социально-философские ценности. 2015. № 3. С. 21 - 55.

5. Тишков В.А. От этноса к этничности и после // Этнографическое обозрение. 2016. № 5. С. 5 - 22.

Ramazanova Patimat Ramazanovna, postgraduate student, Northwest institute of management of the Russian Russian Presidential Academy of National Economy and Public Administration (57/43, Sredny Ave. V.O., St. Petersburg, 199178, Russian Federation). E-mail: pati-agent@mail.ru

\section{DIFFERENTIATION OF ETHNOS AND NATION CONCEPTS IN THE CONDITIONS OF NATIONAL-TERRITORIAL STRUCTURE OF THE RUSSIAN FEDERATION} Abstract

The article is related to the current problem of interethnic and interethnic relations between different social groups, and the prospects for the development of a favorable situation in Russia in matters of ethnic interaction. The article 
deals with the terminology of such concepts as "ethnos", "nation", "people", the question of gradual development of one concept from another and the modern application of these terms at the present time. Particular attention was paid to the concept of "nation" in its negative way and its impact on ethnic groups within States. In conclusion, the prospects of building a multi-ethnic people in Russia, United on the basis of common factors such as the historical path, values and ideas.

Keywords: ethnos, nation, ethnic group, national and territorial device, Russian Federation, people, social groups, multiethnic people, ethnic vzaimodeystvy.

\title{
References
}

1. Ashkhamahova A.A., Dadashev A.A. Sootnoshenie ponyatij «Etnos» i «Naciya»v social'noj filosofii // Obshchestvo: filosofiya, istoriya, kul'tura. 2017. № 7. P. 23-27.

2. Dugin A.G. Sociologiya etnosa. Monografiya. M., 2014. P. 8-14.

3. Paskachev A.B. Nacional'naya politika v Rossii (ot imperii - k edinoj rossijskoj nacii). - M.; YAroslavl': Litera, 2016. $245 \mathrm{~s}$.

4. Semenov YU.I. Obshchestvo, naselenie etnos // Etnos, nacii, cennosti. Social'no-filosofskie cennosti. 2015. № 3. P. $21-55$.

5. Tishkov V.A. Ot etnosa k etnichnosti i posle // Etnograficheskoe obozrenie. 2016. № 5. P. 5 - 22.

УдК 323

DOI: $10.22394 / 2079-1690-2019-1-3-297-302$

\section{ПРЕДСТАВИТЕЛЬСТВА СУБЪЕКТОВ РОССИЙСКОЙ ФЕДЕРАЦИИ: МЕТОДОЛОГИЧЕСКИЕ ОСНОВЫ ИССЛЕДОВАНИЯ}

\author{
Cmenaнов аспирант Института государственной службы и управления, \\ Baдuм Российская академия народного хозяйства и государственной службы \\ Евгеньевич при Президенте РФ (119606, Россия, г. Москва, пр. Вернадского, 84). \\ E-mail: vstepanov777@yandex.ru
}

\section{Аннотация}

Статья посвящена исследованию методологических основ деятельности представительств субъектов Российской Федерации в системе государственного управления. Данные институты, несмотря на свою многолетнюю историю существования, остаются по сей день недостаточно исследованными. Более чем за двадцать лет функционирования представительств субъектов Российской Федерации в современной системе органов власти, их роль и значение так и не стали в научной среде популярным предметом для исследования. Автором делается попытка на основании анализа теории социального действия М. Вебера, теории Ю. Хабермаса о политически функционирующей общественности, теории групп интересов А. Бентли, Д. Трумена, М. Олсона, концепции делегирования П. Бурдье, концепции делегативной демократии Г.О`Доннелла раскрыть сущностные характеристики представительских институтов в системе государственного управления и их значение в процессе реализации политических решений. По итогам статьи автор делает вывод о том, что представительства субъектов Российской Федерации - это институции, представляющие на федеральном уровне определенные группы интересов: официально - регионов России, высшего должностного лица, органов исполнительной власти, а фактически - практически всех ветвей власти, институтов гражданского общества, предпринимательского сообщества. Определяется, что представительства субъектов Российской Федерации - это институализированные формы трансляции политических решений. При этом их функциональное предназначение зависит от приоритетов руководства соответствующих субъектов Российской Федерации.

Ключевые слова: представительство, регион, субъект Российской Федерации, методология, группы интересов, коммуникация, гражданское общество, лоббизм, социальный прогресс.

Представительства субъектов Российской Федерации, несмотря на свою многолетнюю историю существования, остаются по сей день недостаточно исследованными. Более чем за двадцать лет функционирования данного института в современной системе органов власти, его роль и значение так и не стали в научной среде популярным предметом для исследования. Однако в данной статье мы попытаемся определить сущность представительств субъектов Российской Федерации в системе государственного управления, исследовав методологические основы их деятельности.

Автор придерживается позиции, что представительства субъектов Российской Федерации это институты делегирования полномочий, их глубокий анализ возможен при помощи концепции рациональности социального действия М. Вебера [1, с. 602], которая лежит в основе научных взглядов немецкого социолога и философа Ю. Хабермаса. 